\title{
RELAÇÕES PEDOMORFOGEOLÓGICAS NAS CHAPADAS ELEVADAS DO DISTRITO FEDERAL ${ }^{(1)}$
}

\author{
Inara Oliveira Barbosa ${ }^{(2)}$, Marilusa Pinto Coelho Lacerda ${ }^{(3)} \&$ \\ Marina Rolim Bilich ${ }^{(4)}$
}

\begin{abstract}
RESUMO
A caracterização pedológica e o entendimento das relações entre pedologia, geologia e geomorfologia são importantes para a compreensão da distribuição dos solos numa paisagem. O objetivo deste estudo foi avaliar as relações pedomorfogeológicas na região das Chapadas Elevadas do Distrito Federal (DF), mediante caracterização química, física, mineralógica e geoquímica dos solos de ocorrência nesse compartimento da paisagem. Foram selecionadas duas topossequências representativas da distribuição pedológica nas Chapadas Elevadas do DF, cujos solos foram formados a partir de rochas metassedimentares do Grupo Paranoá, representados por Latossolos Vermelhos (LV), Latossolos VermelhoAmarelos (LVA) e Cambissolos (C). Os Latossolos das duas topossequências apresentaram a maioria dos atributos físicos, químicos e mineralógicos semelhantes. A variação da cor nesses Latossolos é proveniente da mineralogia diferenciada dos óxidos de $\mathrm{Fe}$ - hematita predominante nos LV e goethita nos LVA. No entanto, as análises por meio de ICP-AES apresentaram teores de $\mathrm{Fe}_{2} \mathrm{O}_{3}$ similares nos Latossolos, demonstrando material de origem (rochas metassedimentares) de composição geoquímica semelhante. A formação da goethita nos LVA foi considerada dependente da sua posição geomorfológica de desenvolvimento, nas bordas das chapadas, onde a oscilação do lençol freático proporcionou a formação de horizonte litoplíntico, com consequente deficiência das condições de drenagem. Os Cambissolos apresentaram-se quimicamente semelhantes aos Latossolos em razão do material de origem, que são rochas metassedimentares já pré-intemperizadas. O estudo das relações pedomorfogeológicas permitiu constatar que a distribuição dos solos nas Chapadas
\end{abstract}

(1) Parte da Dissertação de Mestrado da primeira autora. Projeto desenvolvido com apoio financeiro do CNPq e FINATEC. Recebido para publicação em outubro de 2008 e aprovado em junho de 2009.

(2) Geóloga do Departamento Nacional de Produção Mineral - DNPM. Quadra 01, Bloco B, CEP 70041-903 Brasília (DF). E-mail: inarabar@yahoo.com.br

(3) Professora Adjunta, Faculdade de Agronomia e Medicina Veterinária, Universidade de Brasília - FAV/UnB. Caixa Postal 4508, CEP 70910-960 Brasília (DF). E-mail: marilusa@unb.br

(4) Engenheira-Agronômica, Companhia Nacional de Abastecimento - CONAB. SGAS 901 Bloco A, Lote 69 - Asa Sul, CEP 70390 010 Brasília (DF). E-mail: maribilich@yahoo.com.br 


\author{
Elevadas do Distrito Federal é condicionada pela evolução geomorfológica e pela \\ geologia da região.
}

Termos de indexação: relações solo-paisagem, rochas metassedimentares, mineralogia do solo, Pedogeoquímica.

\title{
SUMMARY: PEDOMORPHOGEOLOGICAL RELATIONS IN THE CHAPADAS ELEVADAS OF THE DISTRITO FEDERAL, BRAZIL
}

\begin{abstract}
Detailed studies of pedologic characterization, as well as of relationships between pedology, geology and geomorphology are important for the comprehension of the soil distribution in a landscape. The objective of this study was to evaluate the pedomorphogeological relationships in the Chapadas Elevadas of the Distrito Federal, by the chemical, physical, mineralogical and geochemical characterization of the soils found in this landscape compartment. Two representative top-sequences of the pedologic distribution were selected in this geomorphologic unit, whose soils were formed from metasedimentary rocks of the Grupo Paranoá, represented by Red Oxisols (Latosols), Yellow-Red Oxisols and Cambisols. The physical, chemical and mineralogical properties of the Oxisols of the two top-sequences were mostly similar. The color variation in the Oxisols was due to the differentiated Fe oxide mineralogy - predominantly hematite in LV and goethite in LVA. However, the ICP-AES analysis showed similar $\mathrm{Fe}_{2} \mathrm{O}_{3}$ levels in Oxisols, indicating a material of origin (metasedimentary rock) with similar geochemical composition. The goethite formation in LVA was related to the geomorphological position of development, on the edges of the plateau, where the water table oscillation resulted in the formation of a lithoplintic horizon, with consequently deficient drainage conditions. The Cambisols were chemically similar to Oxisols, due to the source material, consisting of preweathered sedimentary rock. The pedomorphogeological relations showed that the soil distribution in the Chapadas Elevadas of the Distrito Federal is linked to the geomorphologic evolution and regional geology.
\end{abstract}

Index terms: Soil-landscape relationships, metasedimentary rock, soil mineralogy, pedogeochemistry.

\section{INTRODUÇÃO}

No Distrito Federal (DF), o substrato litológico apresenta um notável controle da compartimentação e evolução geomorfológica e pedológica associada, segundo Campos (2004), resultando em ambientes pedomorfogeológicos distintos.

O DF está inserido no Bioma Cerrado, onde se apresenta dividido em categorias relacionadas aos tipos de vegetação, como: cerradão, cerrado, campo cerrado, campo sujo, campo limpo e mata galeria. As fitofisionomias apresentam-se, principalmente, relacionadas aos diferentes ambientes pedomorfogeológicos, que resultam da relação de interdependência entre os fatores que condicionam a distribuição dos solos no DF.

Para o processo evolutivo do solo, a participação do relevo é importante, visto que este, de maneira geral, influencia a intensidade do fluxo de água ao longo do perfil de alteração, acelerando as reações químicas do intemperismo, promovendo o transporte de sólidos ou de materiais em solução e produzindo efeitos que se traduzem em diferentes tipos de solo, nas diversas posições geomorfológicas (Carvalho, 1981).

O DF situa-se no Planalto Central do Brasil e, de acordo com Novaes Pinto (1994), apresenta três
Superfícies Geomorfológicas: 1 = Região de Chapadas, 2 = Área de Dissecação Intermediária e 3 = Região Dissecada de Vale. A primeira superfície, mais antiga, corresponde ao antigo peneplano elaborado pelo ciclo de erosão "Sul-Americana" (Braun, 1971), cujos remanescentes constituem as Chapadas Elevadas do Distrito Federal. Essas chapadas apresentam, em quase toda a sua extensão, bordas recobertas por espessa camada de concreções ferruginosas ou canga laterítica (Penteado, 1976; Motta et al., 2002).

Os Latossolos que ocorrem nas Chapadas Elevadas do DF apresentam evolução pedogenética muito acentuada, em razão do grande período de exposição, em ambiente geomorfológico relacionado à superfície geomorfológica "Sul-Americana", de idade Terciária, segundo Rodrigues \& Klamt (1978). Esse ambiente é favorável à atuação do processo de latolização, caracterizando o desenvolvimento de solos de profundidade acentuada, porosidade elevada e quimicamente muito pobres em nutrientes.

Além da intensidade do processo pedogenético em função do relevo plano, aliam-se os materiais de origem, constituídos por rochas metassedimentares psamíticas ou pelíticas do Grupo Paranoá, préintemperizadas na sua gênese sedimentar. A 
composição mineralógica de solos formados em tais condições é, geralmente, constituída por assembleia de minerais cauliníticos e sesquióxidos de $\mathrm{Fe}$ e $\mathrm{Al}$, conforme citado por Mugller et al. (2007). Os Latossolos brasileiros, de modo geral, apresentam mineralogia da fração argila composta por caulinita, gibbsita, goethita e hematita, variando apenas nas suas proporções, em função do grau elevado de intemperização dos minerais primários (Curi \& Franzmeier, 1984; Melo et al., 2001a,b; Resende et al., 2005; Schaeffer et al., 2008).

No Distrito Federal (DF), a principal fonte de informações pedológicas é o levantamento de reconhecimento de solos realizado pela Embrapa (1978), com elaboração de mapa pedológico em escala $1: 100.000$. Os dados disponíveis gerados por essa escala não possibilitam uma caracterização detalhada dos solos e o entendimento das relações entre os seus materiais de origem e superfícies geomorfológicas, responsáveis pela distribuição destes na paisagem do DF.

Entre os solos que ocorrem nas Chapadas Elevadas do DF, destacam-se os Latossolos Vermelhos (LV) nos topos e os Latossolos Vermelho-Amarelos (LVA) nas bordas. A formação preferencial da goethita em relação à hematita nos LVA é relacionada à dissecação geomorfológica da região; entretanto, verifica-se falta de esclarecimento em relação à evolução pedogenética associada e relações de filiação com o material de origem, demandando um estudo mais detalhado das relações pedomorfogeológicas nessa região.

Estudos das relações entre geologia, geomorfologia e solos podem auxiliar o entendimento da ocorrência de solos em uma dada paisagem, assim como avaliações da composição mineralógica e geoquímica dos perfis de alteração podem colaborar no entendimento dos processos de pedogênese. Portanto, o objetivo deste estudo foi avaliar as relações pedomorfogeológicas na região de Chapadas Elevadas do Distrito Federal, mediante caracterização dos atributos químicos, físicos, mineralógicos e geoquímicos dos solos de ocorrência nesse compartimento da paisagem.

\section{MATERIAL E MÉTODOS}

A área de estudo localiza-se no compartimento geomorfológico denominado Chapadas Elevadas do DF, situada na porção centro-oeste do DF, compreendida entre as coordenadas geográficas $15^{\circ} 31^{\prime} 00$ " e $16^{\circ} 03^{\prime} 00$ " de latitude sul e $47^{\circ} 42^{\prime} 00$ " e $48^{\circ} 14^{\prime} 00^{\prime}$ de longitude oeste (Figura 1).

Para realização do trabalho foram selecionadas duas topossequências representativas da distribuição pedológica nas Chapadas Elevadas do DF, que apresentam cotas entre 1.050 e $1.300 \mathrm{~m}$, correspondente à superfície geomorfológica mais antiga do DF, segundo Novaes Pinto (1994), de idade Terciária. As topossequências foram denominadas FAL (Fazenda Água Limpa - FAL da Universidade de Brasília) e Sobradinho, ambas constituídas por sequência de Latossolos Vermelhos, Latossolos Vermelho-Amarelos e Cambissolos Háplicos, todos pertencentes à unidade geomorfológica das Chapadas Elevadas do Distrito Federal, sob vegetação nativa. A primeira localiza-se na Chapada de Brasília e a segunda na Chapada de Sobradinho, ambas constituintes da unidade geomorfológica das Chapadas Elevadas.

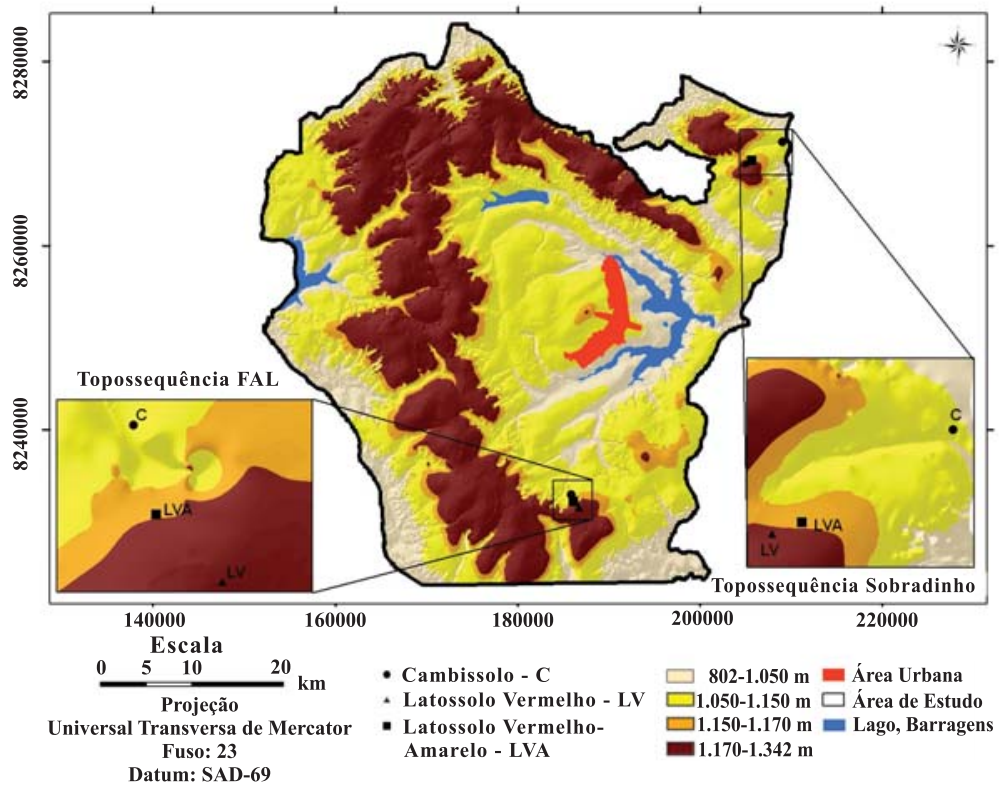

Figura 1. Localização das topossequências estudadas nas Chapadas Elevadas do Distrito Federal (Extraído de Barbosa, 2007). 
Nos Latossolos Vermelhos, a vegetação associada é geralmente de cerrado e cerradão, enquanto nos Latossolos Vermelho-Amarelos a vegetação nativa é cerrado sensu stricto, campo limpo e campo sujo; nas áreas com desenvolvimento de Cambissolos, a vegetação é campo.

Foram selecionados três perfis de solos em cada topossequência, relacionados aos principais solos de ocorrência, distribuídos no topo das chapadas em classes de declividade de $0-4 \%$; próximo às bordas das chapadas, com declividade discretamente maior, entre 4 e $8 \%$; e nas escarpas ou rebordos das chapadas, em classes de declividade mais acentuadas.

A geologia das topossequências é constituída por rochas do Grupo Paranoá de idades Meso/ Neoproterozoicas (1.300 a 1.100 milhões de anos), sendo caracterizadas na topossequência FAL pela unidade litológica denominada Ardósias e, na topossequência Sobradinho, pela unidade Metarritmitos (Freitas-Silva \& Campos, 1998).

O clima predominante da região, segundo a classificação de Köppen, é "tropical de Savana", com a concentração da precipitação pluvial no verão, variando de 2.000 a $1.500 \mathrm{~mm}$. A estação chuvosa começa em outubro e termina em abril, representando $84 \%$ do total anual. O trimestre mais chuvoso é de novembro a janeiro, sendo dezembro o mês de maior precipitação do ano (Ferrante et al., 2001).

Por meio de campanhas de campo, foram realizadas as observações das relações entre os solos, material de origem e relevo (unidades geomorfológicas, classes de declividade e hipsometria). Nas duas topossequências, FAL e Sobradinho, foram realizadas descrições morfológicas e coletadas amostras dos horizontes representativos dos perfis dos solos, para análises químicas, físicas, mineralógicas e geoquímicas, de acordo com Santos et al. (2005). As análises químicas do complexo sortivo e as análises físicas (textura do solo - método do densímetro, umidade gravimétrica e na base de volume e a densidade do solo) foram realizadas segundo métodos descritos em Embrapa (1997).

Quanto à análise da composição mineralógica, foi utilizado o método da difratometria de raios $\mathrm{X}$ nas frações areia $(2-0,05 \mathrm{~mm})$, silte $(0,05-0,002 \mathrm{~mm})$ e argila $(<0,002 \mathrm{~mm})$, individualizadas a partir da Terra Fina Seca ao Ar (TFSA). A fração areia foi obtida por tamisagem em peneiras de 0,053 $\mathrm{mm}$ de malha, após dispersão química com solução normal de hidróxido de sódio e dispersão mecânica. A fração silte + argila foi adquirida pela extração da suspensão silte + argila, após $40 \mathrm{~s}$ da agitação e sedimentação, com base na lei de Stokes. Para separação da fração silte da suspensão silte + argila, adotou-se o processo de centrifugação com rotação em velocidade de $700 \mathrm{rpm}$ por $7 \mathrm{~min} \mathrm{~h}^{-1}$. A fração argila foi adquirida após extração da suspensão constituída somente por argila, de oito em oito horas, após agitação e sedimentação, por quatro dias, também segundo a lei de Stokes. Nos horizontes CR dos Cambissolos estudados foi utilizada a fração TFSA, em função da impossibilidade de individualização das frações areia, silte e argila.

Com as frações separadas, foram feitas lâminas pelo método de esfregaço, encaminhadas para a leitura no difratômetro de raios X RIGAKU, modelo Geiger Fix D-Max-B, pertencente ao Laboratório de Difratometria de raios X do Instituto de Geociências (IG) da Universidade de Brasília. O difratômetro foi operado com tubo de $\mathrm{Cu}$, sob voltagem de $35 \mathrm{kV}$ e $15 \mathrm{~mA}$, velocidade de varredura de $1^{\circ} \mathrm{min}^{-1}$, no intervalo de $2 \theta$ de 2 a $70^{\circ}$. Os resultados foram obtidos em difratogramas, onde os minerais foram identificados com o auxílio do software Jade 3.0 for Windows ${ }^{\circledR} 3.0$ (1995), com banco de dados do ICCD (1996), que faz uma procura automática dos picos dos minerais. A proporção entre caulinita e gibbsita e entre hematita e goethita foi realizada pela avaliação da intensidade dos picos representativos desses minerais.

A análise geoquímica foi realizada na fração TFSA por Espectrometria de Emissão Atômica com Plasma Indutivamente Acoplado (ICP-AES), por meio de ataque triácido (ácido fluorídrico concentrado, ácido perclórico concentrado e ácido clorídrico concentrado) e método de fusão total com metaborato de lítio por emissão atômica. Os elementos maiores determinados foram $\mathrm{Fe}, \mathrm{Ca}, \mathrm{Mg}, \mathrm{K}$ e Ti.

\section{RESULTADOS E DISCUSSÃO}

Nos perfis de solos estudados das topossequências FAL e Sobradinho foram enfatizados os horizontes diagnósticos $\mathrm{B}_{\mathrm{w}}$ e $\mathrm{B}_{\mathrm{i}}$, além dos horizontes $\mathrm{RC}$ e $\mathrm{C}$, presentes nos Cambissolos - estes últimos por demonstrarem filiação com o material de origem.

$\mathrm{Na}$ área estudada, foi confirmada a ocorrência de Latossolos Vermelhos nos topos das Chapadas Elevadas do DF, em relevo plano e suave ondulado, constituindo solos altamente intemperizados, evidenciando processo acentuado de latolização. Já os Latossolos Vermelho-Amarelos ocorrem, principalmente, nas bordas das Chapadas Elevadas e sempre adjacentes aos Latossolos Vermelhos e apresentam horizontes litoplínticos a concrecionários. A presença desses horizontes deve-se à variação de regime hídrico nas bordas das Chapadas, tornando as condições de drenagem interna deficiente, atuando na hidratação dos óxidos de Fe (hematita), transformando em goethita, tal como observado por vários autores, como Martins (2000) e Motta et al. (2002). A classe dos Cambissolos ocorre preferencialmente nas encostas com declividade mais acentuada.

\section{Características químicas e físicas dos solos}

Os solos das topossequências FAL e Sobradinho apresentaram-se química e fisicamente semelhantes, com exceção da textura mais arenosa no LVA da 
topossequência Sobradinho (Quadros 1 e 2). Com relação às análises do complexo sortivo (Quadros $1 \mathrm{e}$ 2), observam-se baixos valores de soma de bases, capacidade de troca catiônica (CTC), saturação por bases e $\mathrm{pH}$; e valores geralmente altos de saturação por $\mathrm{Al}$ - estes últimos particularmente nos solos da topossequência FAL, caracterizando solos distróficos, ácidos e por vezes alumínicos. O comportamento químico dos Cambissolos Háplicos é semelhante ao dos Latossolos em razão dos seus materiais de origem, constituídos por litologias metassedimentares pelíticas e psamíticas do Grupo Paranoá, que são pobres em elementos nutrientes (Barbosa, 2007).

Em relação às características físicas, os solos das duas topossequências estudadas mostraram textura argilosa a muito argilosa, com valores de argila no horizonte $\mathrm{B}_{\mathrm{w}}$ do $\mathrm{LV}$ da topossequência FAL atingindo $890 \mathrm{~g} \mathrm{~kg}^{-1}$, concordando com dados obtidos por Rodrigues \& Klamt (1978) e Gomes et al. (2004) em Latossolos da região. A textura argilosa a muito argilosa dos solos deve-se ao material de origem argiloso correspondente às ardósias e às camadas mais argilosas dos metarritmitos do Grupo Paranoá. Exceção é feita ao LVA da topossequência Sobradinho, que apresenta textura franco-argilo arenosa, em razão da influência das camadas mais arenosas pertencentes ao metarritmito do Grupo Paranoá. Os valores da relação silte/argila no horizonte $\mathrm{B}_{\mathrm{w}}$ dos $\mathrm{LV}$ de ambas as topossequências são muito baixos $(0,06$ e 0,15 , respectivamente no LV - FAL e no LV - Sobradinho), demonstrando o elevado estádio de intemperismo desses solos, conforme estabelecido pelo Sistema Brasileiro de Classificação de Solos - SiBCS (Embrapa, 2006). Na topossequência FAL, o LVA apresenta valor da relação silte/argila discretamente maior do que o do $L V$, podendo indicar evolução pedogenética discretamente menor em relação ao LV.

Na topossequência FAL, os teores de umidade do horizonte $\mathrm{B}_{\mathrm{w}}$ do LVA, tanto em relação à massa (U) quanto ao volume (Ø), apresentam-se discretamente

Quadro 1. Atributos químicos dos solos das topossequências Fazenda Água Limpa - FAL e Sobradinho

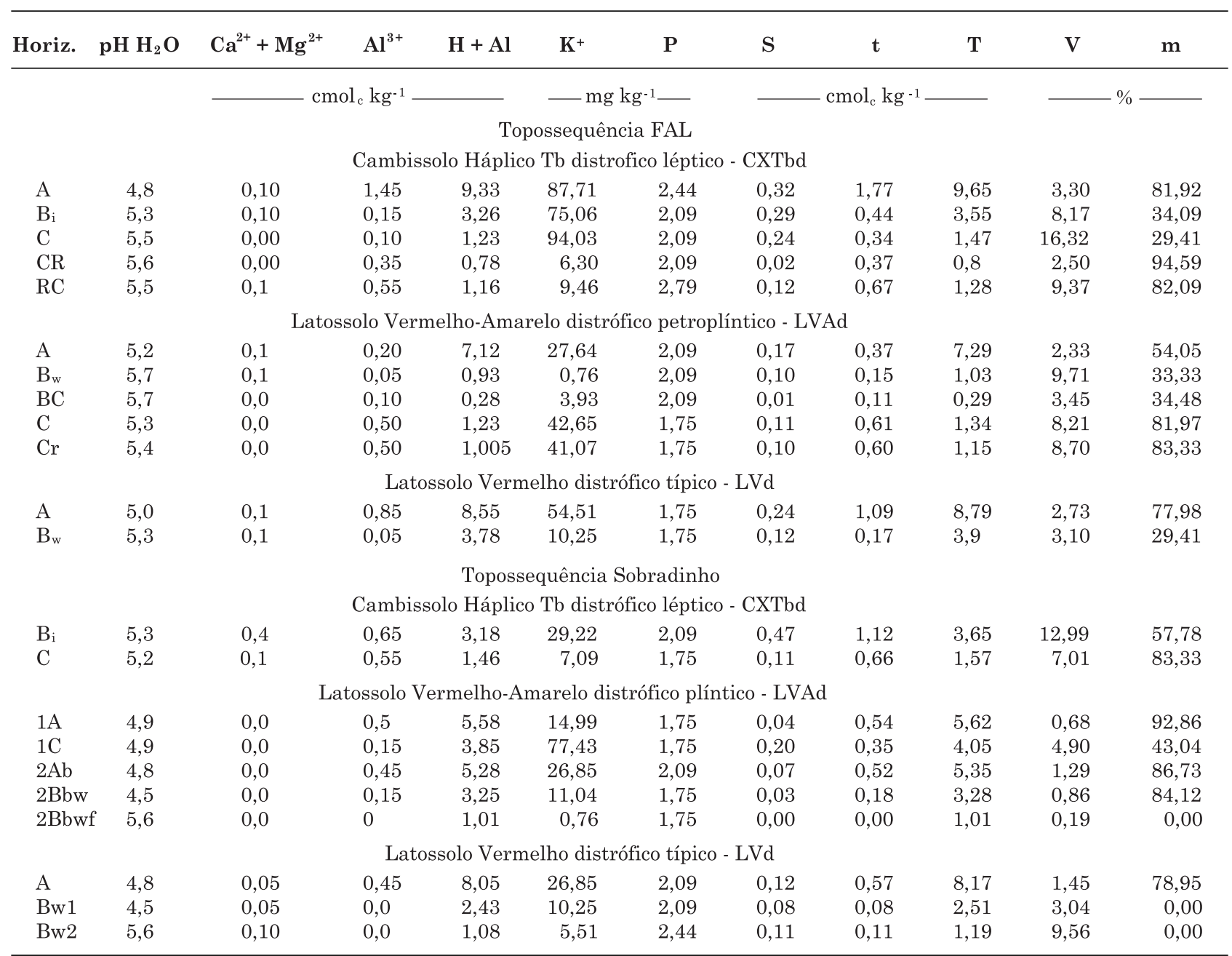

S: soma de bases $\left(\mathrm{Ca}^{2+}+\mathrm{Mg}^{2+}+\mathrm{K}^{+}\right)$; $\mathrm{T}$ : capacidade de troca catiônica $(\mathrm{S}+\mathrm{H}+\mathrm{Al})$; V: saturação por bases $(100 \mathrm{x} \mathrm{S} / \mathrm{T})$ e $\mathrm{m} \%$ : saturação por alumínio $\left(\mathrm{Al}^{3+} \times 100 / \mathrm{t}\right), \mathrm{t}=\mathrm{S}+\mathrm{Al}^{3+}$. 
Quadro 2. Atributos físicos dos solos das topossequências Fazenda Água Limpa - FAL e Sobradinho

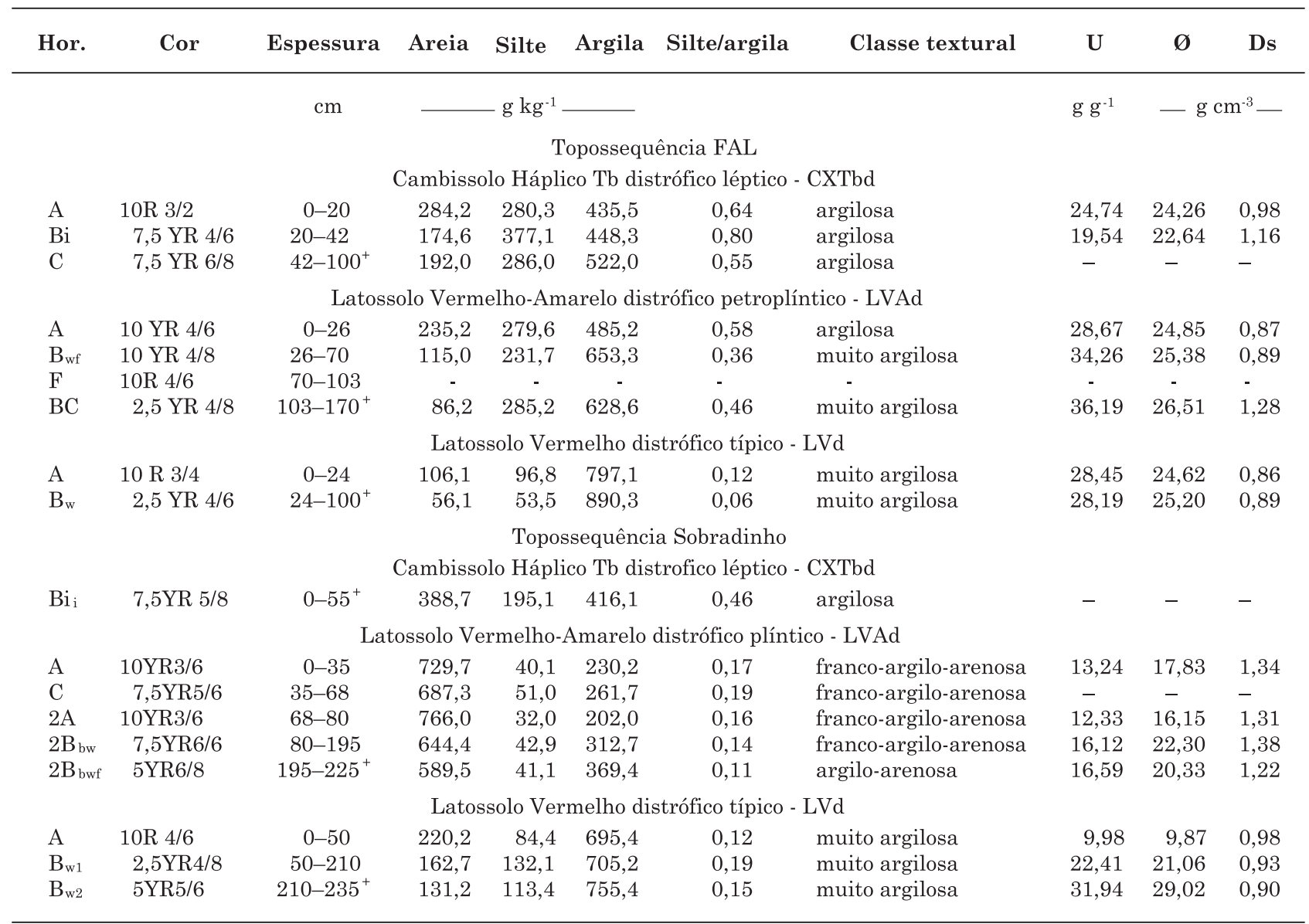

Ds: densidade do solo, U: umidade gravimétrica, Ø: umidade na base de volume.

superiores aos do horizonte $\mathrm{B}_{\mathrm{w}}$ do LV, mesmo na época da coleta das amostras, que coincidiu com a estação seca prolongada no DF. Provavelmente, a maior umidade verificada no LVA esteja relacionada à deficiência de drenagem interna, que proporciona maior permanência do lençol freático no LVA, em razão da presença de horizonte litoplíntico a concrecionário. Já o LVA da topossequência Sobradinho não apresentou essa tendência, devido à textura mais arenosa, que proporciona maior permeabilidade da água, além do menor impedimento da drenagem interna em decorrência da presença de petroplintitas menos evoluídas em relação ao LVA da topossequência FAL, onde o horizonte litoplíntico a concrecionário é mais desenvolvido.

A gênese do horizonte litoplíntico nos LVA está relacionada à sua distribuição nas Chapadas Elevadas, desenvolvendo-se próximo às suas bordas, onde a declividade apresenta discreto acréscimo e oscilações do lençol freático, proporcionando assim, a estabilização da goethita, concordando com Motta et al. (2002) e Resende et al. (2005).

\section{Características mineralógicas dos solos}

Em ambas as topossequências avaliadas, as análises de difração de raios $\mathrm{X}$ da fração areia demonstraram que o quartzo é o mineral dominante, tal como constatado por diversos estudos envolvendo mineralogia de Latossolos da região, como os de Melo et al. (2001a,b), Gomes et al. (2004) e Muggler et al. (2007) (Figura 2a,b).

A mineralogia da fração argila dos horizontes $B_{w}$ dos Latossolos (LV e LVA) de ambas as topossequências é constituída basicamente por caulinita $(\mathrm{Ct})$, gibbsita (Gb), hematita (Hm) e goethita (Gt) (Figura 2a,b).

$\mathrm{Na}$ topossequência FAL, verificou-se $\mathrm{Gb}>\mathrm{Ct}$ no Latossolo Vermelho, mostrando discreto acréscimo na evolução dos processos pedogenéticos no LV em relação ao LVA, tal como indicado pela variabilidade dos valores da relação silte/argila constatada nesses solos. Essa evolução pedogenética ligeiramente mais pronunciada, provavelmente, está condicionada pela presença do horizonte litoplíntico no LVA, já que os demais fatores genéticos são semelhantes. Assim, o 
LVA é mais raso que o $\mathrm{LV}$, apresentando horizonte $\mathrm{BC}$ em profundidade de cerca de $2,5 \mathrm{~m}$, ao passo que o $\mathrm{LV}$ apresenta horizonte $\mathrm{B}_{\mathrm{w}}$ com espessuras atingindo 20-30 m. Isso foi verificado em diversos locais das Chapadas Elevadas do DF. Ressalta-se ainda que, quando o material de origem é constituído por rochas de origem sedimentar, que é o caso dos solos estudados, a caulinita ainda pode permanecer nos solos (Nahon, 1991).

O LVA da topossequência Sobradinho apresentou duas sequências sotopostas, com horizontes definidos como A e C para a primeira e $2 \mathrm{~A}_{\mathrm{b}}, 2 \mathrm{~B}_{\mathrm{bw}}$ e $2 \mathrm{~B}_{\mathrm{bwf}}$ para a segunda. A relação $\mathrm{Gb} / \mathrm{Ct}$ na fração argila dos horizontes $2 \mathrm{~A}_{b}$ e $2 \mathrm{~B}_{\mathrm{bw}}$ mostrou padrão similar ao do LV da mesma topossequência, denotando materiais semelhantes.

A relação $\mathrm{Hm} / \mathrm{Gt}$ foi considerada maior nos $\mathrm{LV}$ em relação aos LVA nas duas topossequências estudadas, sendo maior no LV da topossequência FAL em comparação ao LV da topossequência Sobradinho (Figura 2a,b). O maior conteúdo de Hm do LV-FAL, provavelmente, está relacionado ao material de origem - ardósias, que apresentam maior teor de ferro do que as camadas argilosas do metarritmito, que constitui a litologia de origem do LV - Sobradinho. Nos LVA das topossequências estudadas, o predomínio é da goethita em relação à hematita; além da variação do material de origem, acrescentam-se as condições de drenagem interna deficiente nos LVA, que favorece a estabilidade da goethita em relação à hematita (Macedo, 1988).

A variação $\mathrm{Hm}>$ Gt descrita para os $\mathrm{LV}$ não se apresenta muito destacada nos difratogramas estudados, pois os óxidos de ferro, devido ao seu pequeno tamanho e grau de cristalinidade variável, muitas vezes requerem, para seu estudo, técnicas mais sofisticadas, em adição à difração de raios $\mathrm{X}$ (Resende et al., 2005). Deve-se destacar, também, que o Fe pode participar da estrutura da gibbsita e caulinita por processos de substituição isomórfica. Muggler et al. (2007) observaram a presença de ferro na estrutura da caulinita por substituição isomórfica do $\mathrm{Al}$ pelo $\mathrm{Fe}$. $\mathrm{O}$ processo de ferruginização da caulinita ocorre com a substituição epigenética das camadas da caulinita por meio de cristais de hematita ou por dissolução da caulinita, como resultado da ferrólise (Brinkman, 1979). $\mathrm{O} \mathrm{Fe}^{3+}$ é reduzido em condições de saturação por água, e a solução com $\mathrm{Fe}^{2+}$ pode, então, fluir entre as camadas da caulinita, que é dissolvida no processo de redução. Quando a caulinita se cristaliza novamente, acomoda um pouco de ferro dentro da sua estrutura.

$\mathrm{Na}$ fração argila do horizonte BC do LVA da topossequência FAL, verificou-se a presença de illita, juntamente com caulinita e traços de gibbsita (Figura 2c), demonstrando o menor grau de evolução pedogenética ou relictos do material de origem ardósias, onde a illita é mineral comum. (a)

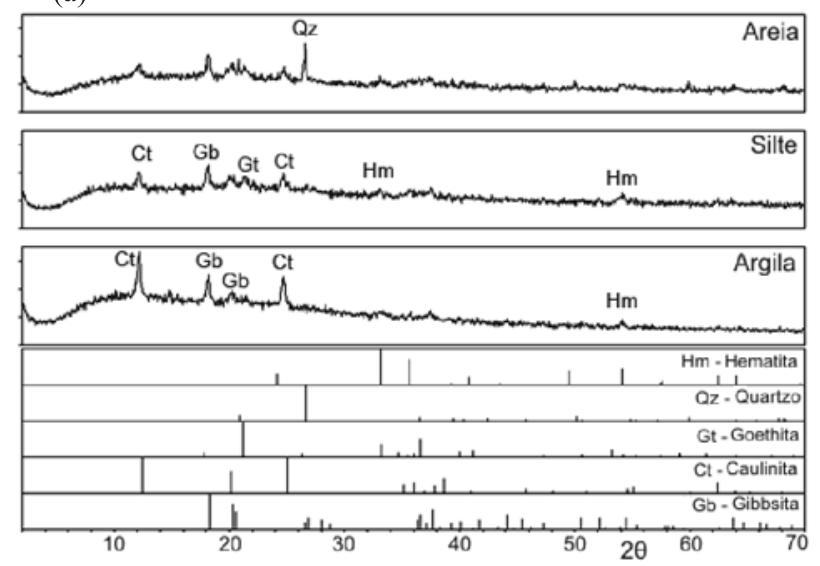

(b)
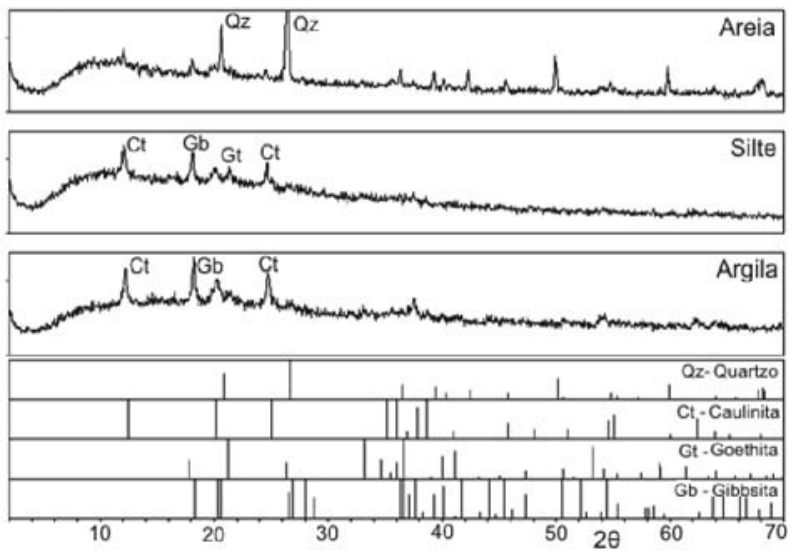

(c)
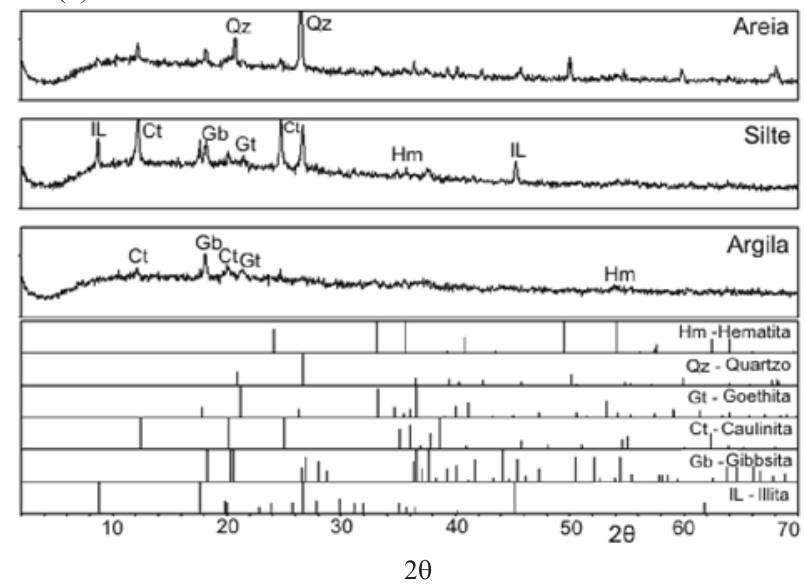

Figura 2. Difratogramas de raios $X$ dos Latossolos das topossequências Fazenda Água Limpa (FAL) e Sobradinho: (a) frações areia, silte e argila do horizonte $B_{w}$ do LV da topossequência FAL; (b) frações areia, silte e argila do horizonte $B_{w}$ do LV da topossequência Sobradinho; (c) frações areia, silte e argila do horizonte $\mathrm{BC}$ do LVA da topossequência FAL. As barras representam a posição característica (valor $2 \theta$ ) e a intensidade dos picos dos minerais nos difratogramas. 
A composição mineralógica dos Cambissolos Háplicos das topossequências estudadas apresenta quartzo, caulinita e illita nas frações TFSA avaliadas nos horizontes CR (FAL) e CR (Sobradinho) (Figura 3a,b). Nos demais horizontes avaliados, verificou-se o aparecimento de goethita e gibbsita nas frações silte e argila. A relação Gb/Ct na fração argila demonstrou que a gibbsita aumenta em relação à caulinita nos horizontes $B_{i}$. No entanto, a relação $\mathrm{Gb} / \mathrm{Ct}$ mostrou que a caulinita predomina sobre a gibbsita, provavelmente devido à presença de caulinita nos materiais de origem de ambos os Cambissolos estudados. A illita ocorre nos horizontes $\mathrm{C}$ e CR e nas frações silte dos horizontes $\mathrm{B}_{\mathrm{i}} \mathrm{e} \mathrm{A}$, possivelmente, pelo processo pedogenético de bissialitização ao longo do perfil de alteração (Loughnan, 1969).

Entre os óxidos de ferro, nos Cambissolos Háplicos das duas topossequências foi constatada a ocorrência somente de goethita em todos os horizontes, demonstrando o estádio inicial de intemperização, em que o primeiro mineral de ferro a se formar é a goethita
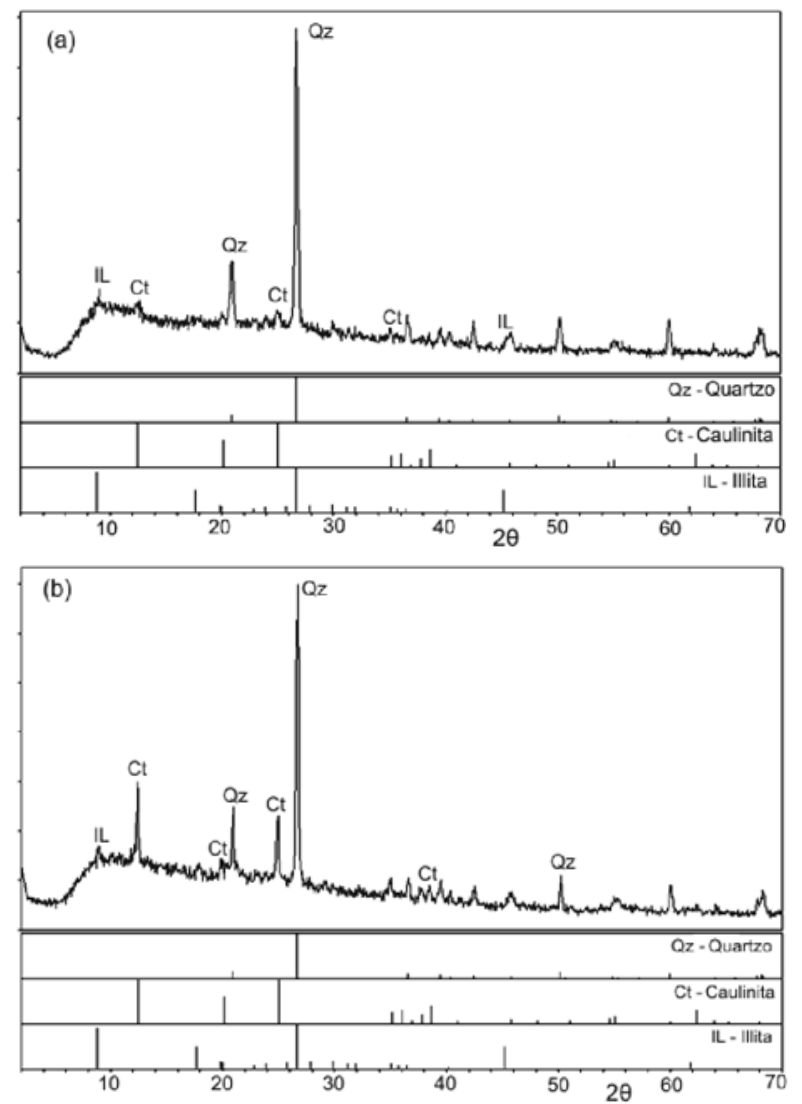

Figura 3. Difratogramas de raios X dos Cambissolos Háplicos das topossequências Fazenda Água Limpa (FAL) e Sobradinho: (a) fração TFSA do horizonte CR do CX da topossequência FAL; (b) fração TFSA do horizonte CR do CX da topossequência Sobradinho. As barras representam a posição característica (valor $2 \theta$ ) e a intensidade dos picos minerais nos difratogramas.
(Kämpf \& Schwetmann, 1995), o que mostra o grau limitado de intemperização desses solos.

\section{Características geoquímicas dos solos estudados}

A topossequência FAL apresentou teores mais elevados de $\mathrm{Fe}_{2} \mathrm{O}_{3}$, devido ao material de origem ardósias ferruginosas do Grupo Paranoá, onde o horizonte RC do Cambissolo Háplico apresentou teor de 63,8 $\mathrm{g} \mathrm{kg}^{-1}$ e o horizonte Cr do LVA, de 45, $0 \mathrm{~g} \mathrm{~kg}^{-1}$, seguido de enriquecimento ao longo dos seus horizontes, nos perfis de alteração tanto dos Cambissolos quanto dos Latossolos, atingindo $133,0 \mathrm{~g} \mathrm{~kg}^{-1}$ no horizonte $\mathrm{B}_{\mathrm{w}}$ do Latossolo Vermelho-Amarelo (Quadro 3). Assim, a composição mineralógica, que mostra predomínio de goethita em relação à hematita no LVA, não é em função do teor de $\mathrm{Fe}_{2} \mathrm{O}_{3}$ do material de origem, sendo originada dos problemas de drenagem interna provocados pelo horizonte litoplíntico a concrecionário, que atinge teor de $\mathrm{Fe}_{2} \mathrm{O}_{3}$ de $440 \mathrm{~g} \mathrm{~kg}^{-1}$. O horizonte litoplíntico constitui uma barreira na drenagem do solo, proporcionando a variação do regime hídrico do lençol freático. Desse modo, ocorre hidratação da hematita e sua transformação em goethita, como observado por Macedo (1988) e Motta et al. (2002).

Os teores de $\mathrm{Fe}_{2} \mathrm{O}_{3}$ mostraram-se semelhantes aos encontrados por Marques et al. (2004) nos estudos realizados na Superfície Sul-Americana, na região de Luziânia e Silvânia, relacionada às Chapadas Elevadas no DF.

Já o Cambissolo da topossequência Sobradinho apresenta menores valores de $\mathrm{Fe}_{2} \mathrm{O}_{3}\left(34,3 \mathrm{~g} \mathrm{~kg}^{-1}\right)$ no horizonte $\mathrm{C}$ em relação ao Cambissolo da topossequência FAL, que apresenta valores de $143,2 \mathrm{~g} \mathrm{~kg}^{-1}$, em razão da diferença dos materiais de origem desses solos nas topossequências estudadas, constituídos por metarritmitos e ardósias do Grupo Paranoá, respectivamente.

O LVA da topossequência Sobradinho mostrou menor teor de $\mathrm{Fe}_{2} \mathrm{O}_{3}$ em relação ao LVA - FAL, provavelmente pelo fato de a formação do solo ter ocorrido a partir das camadas mais arenosas do metarritmito. Já o LV apresentou teores de $\mathrm{Fe}_{2} \mathrm{O}_{3}$ compatíveis aos do LV da FAL, devido ao material de origem ser predominantemente constituído pelas camadas mais argilosas do metarritmito, que contêm teores de $\mathrm{Fe}_{2} \mathrm{O}_{3}$ mais altos.

A análise geoquímica mostrou valores baixos de $\mathrm{CaO}$ e teores significativos de $\mathrm{MgO}$ e $\mathrm{K}_{2} \mathrm{O}$, destacandose os teores deste último, provavelmente em decorrência da presença nesses solos de argilominerais $2: 1$, particularmente a illita, nas frações areia dos Latossolos e também nas frações argila dos Cambissolos. Esses valores foram considerados importantes para os Latossolos das duas topossequências estudadas, que são solos altamente intemperizados, com alta taxa de lixiviação desses elementos, os quais apresentam mobilidade alta. Os 
Quadro 3. Atributos geoquímicos dos solos das topossequências Fazenda Água Limpa - FAL e Sobradinho

\begin{tabular}{|c|c|c|c|c|c|}
\hline Horiz. & $\mathrm{Fe}_{2} \mathrm{O}_{3}$ & $\mathrm{CaO}$ & MgO & $\mathbf{K}_{2} \mathbf{O}$ & $\mathrm{TiO}_{2}$ \\
\hline & \multicolumn{5}{|c|}{$\mathrm{g} \mathrm{kg}^{-1}$} \\
\hline \multicolumn{6}{|c|}{ Topossequência FAL } \\
\hline \multicolumn{6}{|c|}{ Cambissolos Háplicos Tb distróficos lépticos CXTbd } \\
\hline A & 58,3 & 0,1 & 1,7 & 5,2 & 9,0 \\
\hline $\mathrm{B}_{\mathrm{i}}$ & 80,0 & 0,2 & 1,9 & 6,7 & 9,5 \\
\hline $\mathrm{C}$ & 143,0 & 0,2 & 1,9 & 6,9 & 8,9 \\
\hline $\mathrm{CR}$ & 36,5 & 0,2 & 1,8 & 5,4 & 5,0 \\
\hline $\mathrm{RC}$ & 63,8 & 0,2 & 2,7 & 12,0 & 8,1 \\
\hline \multicolumn{6}{|c|}{ LVA distrófico petroplíntico - LVAd } \\
\hline A & 115,0 & 0,02 & 1,1 & 2,3 & 4,5 \\
\hline $\mathrm{B}_{\mathrm{w}}$ & 133,0 & 0,01 & 1,2 & 2,9 & 16,8 \\
\hline $\mathrm{F}$ & 440,0 & 0,01 & 4,1 & 14,0 & 7,1 \\
\hline $\mathrm{BC}$ & 120,0 & 0,01 & 2,2 & 6,2 & 14,6 \\
\hline $\mathrm{C}$ & 76,8 & 0,11 & 3,8 & 12,0 & 10,7 \\
\hline $\mathrm{Cr}$ & 45,0 & 0,02 & 2,2 & 6,5 & 6,0 \\
\hline \multicolumn{6}{|c|}{ LV distrófico típico - LVd } \\
\hline $\mathrm{A}$ & 127,0 & 0,05 & 0,4 & 0,6 & 17,7 \\
\hline $\mathrm{B}_{\mathrm{w}}$ & 81,3 & 0,02 & 1,3 & 3,6 & 7,7 \\
\hline \multicolumn{6}{|c|}{ Topossequência Sobradinho } \\
\hline \multicolumn{6}{|c|}{ Cambissolos Háplicos Tb distróficos lépticos - CXTbd } \\
\hline $\mathrm{B}_{\mathrm{i}}$ & 54,3 & 0,2 & 2,4 & 2,9 & 8,0 \\
\hline $\mathrm{C}$ & 34,3 & 0,1 & 3,1 & 4,1 & 5,4 \\
\hline $\mathrm{CR}$ & 21,1 & 0,4 & 9,1 & 15,1 & 14,7 \\
\hline \multicolumn{6}{|c|}{ LVA distrófico plíntico - LVAd } \\
\hline $1 \mathrm{~A}$ & 39,4 & 0,2 & 0,1 & 0,6 & 5,3 \\
\hline $1 \mathrm{C}$ & 51,0 & 0,2 & 0,2 & 0,7 & 8,6 \\
\hline $2 \mathrm{~A}_{\mathrm{b}}$ & 30,6 & 0,1 & 0,1 & 0,6 & 4,8 \\
\hline $2 \mathrm{~B}_{\mathrm{bwf}}$ & 41,1 & 0,1 & 0,2 & 0,6 & 7,3 \\
\hline $2 \mathrm{~B}_{\mathrm{bw}}$ & 59,2 & 0,2 & 0,2 & 0,7 & 10,5 \\
\hline \multicolumn{6}{|c|}{ LV distrófico típico - LVd } \\
\hline A & 110,6 & 0,1 & 0,3 & 0,5 & 18,7 \\
\hline $\mathrm{B}_{\mathrm{w} 1}$ & 103,5 & 0,1 & 0,3 & 0,3 & 18,5 \\
\hline $\mathrm{B}_{\mathrm{w} 2}$ & 113,9 & 0,1 & 0,3 & 0,4 & 20,7 \\
\hline
\end{tabular}

maiores teores foram observados nos Cambissolos Háplicos $\mathrm{Tb}$ distróficos lépticos de ambas as topossequências, por serem solos jovens, onde o processo de intemperismo foi menos atuante. Segundo Melo et al. (2001a), mesmo em baixa quantidade, a illita é responsável pelos teores totais de $\mathrm{K}_{2} \mathrm{O}$ em solos altamente intemperizados. Nas frações areia dos solos estudados não foi encontrada illita. Ela só foi observada no LVA da FAL no horizonte BC.

$\mathrm{Na}$ topossequência FAL, os teores de $\mathrm{TiO}_{2}$ aumentaram ao longo dos perfis de alteração estudados, pois são elementos normalmente associados ao $\mathrm{Fe}_{2} \mathrm{O}_{3}$. Os valores desse elemento foram considerados altos para as duas topossequências, onde os materiais de origem são rochas metassedimentares psamopelíticas.

\section{Relação entre solos, material de origem e geomorfologia na distribuição na paisagem}

As duas topossequências permitiram observar estreita relação dos materiais de origem com os solos formados, apesar da pequena variação das litologias de origem. Isso indica que os solos das Chapadas Elevadas do Distrito Federal tiveram desenvolvimento in situ, com pequena contribuição coluvionar localizada, sem variações significativas nas composições dos materiais de origem.

Apesar da grande evolução pedogenética dos Latossolos, foi possível identificar variações nos graus de seu desenvolvimento, particularmente na topossequência FAL, em que o LVA mostra-se discretamente menos desenvolvido e menos profundo em relação ao $\mathrm{LV}$, podendo ser observado e estudado seu material de origem nos horizontes BC-C-Cr. O predomínio da goethita em relação à hematita nos LVA não está relacionado somente ao material de origem, composicionalmente semelhante ao do LV, mas se deve também às condições de drenagem, que permitiram a maior estabilidade da goethita em relação à hematita, em razão da presença de horizonte litoplíntico.

O controle da distribuição dos solos nas Chapadas Elevadas do DF está condicionado principalmente à evolução morfogenética da paisagem, ou seja: a Primeira Superfície Geomorfológica do Distrito Federal corresponde ao antigo peneplano elaborado pelo ciclo de erosão "Sul-Americana" (Braun, 1971), cujos remanescentes constituem as chapadas atuais com desenvolvimento dos Latossolos Vermelhos, e suas bordas são recobertas, em quase toda a extensão, por LVA com horizonte litoplíntico. A transição da Primeira para a Segunda Superfície estende-se na forma de plano inclinado a partir das bordas da primeira em direção aos principais cursos d'água, com desenvolvimento preferencial dos Cambissolos.

A geologia é um fator importante na sustentação das bordas das chapadas no processo de dissecação do relevo, por meio da camada de quartzito (unidade Q3) do Grupo Paranoá, proporcionando a preservação do compartimento geomorfológico das Chapadas Elevadas em cotas entre 1.050 e 1.300 m, com idade Terciária. No processo de dissecação, a oscilação do lençol freático promoveu a plintitização e posterior formação das petroplintitas, que, atualmente auxiliam a sustentação das bordas dessas chapadas. Esse processo atingiu os Latossolos próximos às bordas das chapadas, originando o horizonte litoplíntico a concrecionário e a consequente estabilização da goethita nos Latossolos Vermelho-Amarelos atuais.

\section{CONCLUSÕES}

1. Os solos estudados nas duas topossequências representativas das Chapadas Elevadas do Distrito 
Federal apresentaram características químicas, físicas e mineralógicas semelhantes, com variações discretas relacionadas aos materiais de origem.

2. A composição mineralógica dos solos das duas topossequências é constituída por caulinita, gibbsita, goethita e hematita, com variações nas proporções entre $\mathrm{Gb} / \mathrm{Ct}$ e $\mathrm{Hm} / \mathrm{Gt}$, em função do grau de evolução dos solos e material de origem.

3. O predomínio da goethita em relação à hematita e a presença de horizonte litoplíntico nos Latossolos Vermelho-Amarelos devem-se às condições de drenagem nos perfis.

\section{LITERATURA CITADA}

BARBOSA, I.O. Distribuição dos solos nas Chapadas Elevadas do Distrito Federal, com emprego de geoprocessamento. Brasília, Universidade de Brasília, 2007. 125p. (Tese de Mestrado)

BRAUN, O.P.G. Contribuição à geomorfologia do Brasil Central. R. Bras. Geogr., 32:3-39, 1971.

BRINKMAN, R. Ferrolysis, a soil forming process in hydromorphic conditions. Agric. Res. Reports, 887:1-106, 1979.

CAMPOS, J.E.G. Hidrogeologia do Distrito Federal: Bases para a gestão dos recursos hídricos subterrâneos. R. Bras. Geoci., 34:41-48, 2004.

CARVALHO, W.A. Relações entre relevo e solos da bacia do Rio Capivara - município de Botucatu, SP. São Paulo, Universidade Estadual do Estado de São Paulo, 1981. 193p. (Tese de Doutorado)

CURI, N. \& FRANZMEIER, D.P. Toposequence of Oxisols from the Central Plateau of Brazil. Soil Sci. Soc. Am. J., 48:341-346, 1984.

EMPRESA BRASILEIRA DE PESQUISA AGROPECUÁRIA EMBRAPA. Centro Nacional de Pesquisas de Solos. Levantamento de Reconhecimento dos Solos do Distrito Federal. Rio de Janeiro, 1978. 455p (Boletim Técnico, 53)

EMPRESA BRASILEIRA DE PESQUISA AGROPECUÁRIA EMBRAPA. Centro Nacional de Pesquisas de Solos. Manual de métodos de análise de solo. 2.ed. Rio de janeiro, 1997. $212 \mathrm{p}$

EMPRESA BRASILEIRA DE PESQUISA AGROPECUÁRIA EMBRAPA. Centro Nacional de Pesquisas de Solos. Sistema brasileiro de classificação de solos. Brasília, Serviço de Produção de Informação, 2006. 412p.

FERRANTE, E.T.; RANCAN, L. \& NETTO, P.B. Meio físico clima. In: FONSECA, F.O., org. Olhares sobre o Lago Paranoá. Brasília, Secretaria de Meio Ambiente e Recursos Hídricos do Distrito Federal, 2001. v.1. CD ROOM.
FREITAS-SILVA, F.H. \& CAMPOS, J.E.G. Geologia do Distrito Federal. In: CAMPOS, J.E.G. \& FREITAS-SILVA, F.H., coords. Inventário hidrogeológico e dos recursos hídricos superficiais do Distrito Federal. Brasília, SEMATECIEMA-MMA-SRH, 1998. CD-ROM.

GOMES, J.B.V.; CURI, N.; MOTTA, P.E.F.; KER, J.C.; MARQUES, J.J.G.S.M. \& SCHULZE, D.G. Análise de componentes principais de atributos físicos, químicos e mineralógicos de solos do bioma Cerrado. R. Bras. Ci. Solo, 28:137-153, 2004.

INTERNATIONAL CENTER OF DIFFRACTION DATA ICCD. Power Diffraction File - PDF for the PC. International Center of Diffraction Data: Material Data, 1996. CD-ROM.

JADE for Windows ${ }^{\circledR}$ 3.0. XRD pattern processing for the PC. Livermore, Material Data, 1995. CD-ROM.

KÄMPF, N. \& SCHWETMANN, U. Goethita na interface solorocha em amostras do Rio Grande do Sul e Minas Gerais. R. Bras. Ci. Solo, 19:359-366, 1995.

LOUGHNAN, F.C. Chemical weathering of the silicate minerals. New York, Elesevier, 1969. 154p.

MARTINS, E.S. Petrografia, mineralogia e geomorfologia de regolitos lateríticos no Distrito Federal. Brasília, Universidade de Brasília, 2000. 196p. (Tese de Doutorado)

MACEDO, J. Preferential reduction of hematite over goethite in some Oxisols in Brazil. Cornell, Cornell University, 1988. 43p. (Tese de Doutorado)

MARQUES, J.J.G.S.M.; SCHULZE，D.G.; CURI，N. \& MERTZMAN, S.A. Major element geochemistry and geomorphic relationships in Brazilian cerrado soils. Geoderma, 119:179-195, 2004.

MELO, V.F.; SINGH, B.; SCHAEFER, C.E.G.R.; NOVAIS, R.F. \& FONTES, M.P.F. Chemical and mineralogical properties of Kaolinite-rich Brazilian soils. Soil Sci. Soc. Am. J., 65:324-1333, 2001a.

MELO, V.F. FONTES, M.P.F.; NOVAIS, R.F.; SINGH, B. \& SCHAEFER, C.E.G.R. Características dos óxidos de ferro e de alumínio de diferentes classes de solos. R. Bras. Ci. Solo, 25:19-32, 2001b.

MOTTA, P.E.F.; CARVALHO FILHO, A.; KER, J.C. \& PEREIRA, N.R. Relações solo-superfície geomórfica e evolução da paisagem em uma área do planalto central brasileiro. Pesq. Agropec. Bras., 37:869-878, 2002.

MUGGLER, C.C.; BUURMAN, P. \& van DOESBURG, J.D.J. Weathering trends and parent material characteristics of polygenetic Oxisols from Minas Gerais, Brazil: I. Mineralogy. Geoderma, 138:39-48, 2007.

NAHON, D.B. Introduction to the petrology of soils and chemical weathering. New York, John Wiley \& Sons, 1991. 313p.

NOVAES PINTO, M. Caracterização geomorfológica do Distrito Federal. In: NOVAES PINTO, M., org. Cerrado: Caracterização, ocupação e perspectivas. Brasília, Universidade de Brasília/SEMATEC, 1994. p.285-344.

PENTEADO, M.M. Tipos de concreções ferruginosas nos compartimentos geomorfológicos do Planalto de Brasília, Not. Geomorfol.,16:39-53, 1976. 
RESENDE, M.; CURI, N.; KER, J.C. \& REZENDE, S.B. Mineralogia de solos brasileiros: Interpretações e aplicações. Lavras, Universidade Federal de Lavras, 2005. $192 \mathrm{p}$.

RODRIGUES, T.E. \& KLAMT, E. Mineralogia e gênese de uma sequência de solos do Distrito Federal. R. Bras. Ci. Solo, 5:132-139, 1978.
SANTOS, R.D.; LEMOS, R.C.; SANTOS, H.G.; KER, J.C. \& ANJOS, L.H.C. Manual de descrição e coleta de solo no campo. Viçosa, MG, Sociedade Brasileira de Ciência do Solo, 2005. 100p.

SCHAEFFER, C.E.G.R.; FABRIS, J.D. \& KER, J.C. Minerals in the clay fraction of Brazilian Latosols (Oxisols): A review. Clay Miner., 43:137-154, 2008. 